\title{
Do Physicians Address Other Medical Problems During Preventive Gynecologic Visits?
}

\author{
Donna Cohen, MD, MSc, and Andrew Coco, MD, MS
}

Background: The patient-centered medical home model may be a strategic approach to improve delivery of women's health care and consistently provide women with accessible and comprehensive care. We examined whether primary care physicians (family medicine, internal medicine, and hospital general medicine clinics) and obstetrician-gynecologists differ in scope and the number of medical issues addressed during preventive gynecologic visits.

Methods: We analyzed data from the National Ambulatory Medical Care Survey and National Hospital Ambulatory Medical Care Survey to characterize visits with a primary diagnosis of gynecological examination or routine cervical Papanicolaou test between 1999 and 2008. We compared the number and type of concurrent nongynecologic diagnoses addressed by primary care physicians and obstetriciangynecologists during visits.

Results: A total of $\mathbf{7 8 8 2}$ visits were included, representing 271 million primary visits for Papanicolaou tests. Primary care physicians were 2.41 times more likely to include one or more concurrent medical diagnoses during the preventive gynecologic visit compared with obstetrician-gynecologists (odds ratio, $2.41 ; 95 \%$ confidence interval, $1.63-3.57)$.

Conclusions: Primary care physicians are significantly more likely to address concurrent medical problems during preventive gynecologic visits compared with obstetrician-gynecologists. These findings demonstrate the vital role of primary care physicians in providing comprehensive health care to women, consistent with principles of the patient-centered medical home model. (J Am Board Fam Med 2014;27:13-18.)

Keywords: Gynecology, Medical Home, Papanicolaou Test, Patient-Centered Care, Preventive Health Services, Primary Health Care, Women's Health

The patient-centered medical home and its key principles, including accessible, comprehensive, coordinated, and patient-centered care, have gained increasing attention as a national model to improve

This article was externally peer reviewed.

Submitted 24 January 2013; revised 2 July 2013; accepted 10 July 2013.

From The Research Institute and the Department of Family and Community Medicine, Lancaster General Hospital, Lancaster, PA.

Funding: none.

Prior presentation: Society of Teachers of Family Medicine Annual Conference, New Orleans, LA, April 27 to May 1, 2011; the Pennsylvania Academy of Family Physicians Research Day, State College, PA, March 12, 2011.

Conflict of interest: none declared.

Corresponding author: Donna Cohen, MD, MSc, 540 North Duke Street, Lancaster, PA 17604 (E-mail: docohen@ lghealth.org).

See Related Commentary on Page 8. the organization and delivery of primary health care. ${ }^{1-4}$ In this model, a personal physician provides preventive, chronic, and acute services so that patients can receive continuous, integrated care throughout their lifetime. ${ }^{1-4}$ These principles may have particularly significant implications for the delivery of women's health care because women may sometimes require multiple visits with different providers and systems to address their gynecologic and medical needs. ${ }^{5-14}$

For many women, a preventive gynecological visit may be their sole contact with medical care and an opportunity to address coexisting concerns and medical issues. Family medicine, internal medicine, and obstetrics/gynecology all provide care to women, but the extent to which they address multiple medical problems during a single encounter is unknown. Improved knowledge of the breadth and scope of care being provided during primary preventive gynecologic visits may have important implications for women's 
health care as we move forward with instituting patientcentered policies and models of care.

The aim of this study was to compare the number and type of concurrent medical diagnoses addressed by primary care physicians and obstetrician-gynecologists during visits with a primary purpose of gynecological examination or routine cervical Papanicolaou test. We analyzed data from the National Ambulatory Medical Care Survey (NAMCS) and National Hospital Ambulatory Medical Care Survey (NHAMCS) between the years of 1999 and 2008.

\section{Methods}

\section{Design of NAMCS and NHAMCS}

The NAMCS and NHAMCS, conducted by the National Center for Health Statistics (NCHS), contain nationally representative data on ambulatory visits in the United States. NAMCS collects information on patient visits to community, office-based physician practices, including visits to federally qualified health centers and nonfederal government clinics. The database incorporates a multistage probability design, accounting for geographic location, physician specialty, and individual patient visits within the practice. Physicians are randomly selected and assigned to a 1 -week reporting period. Data for a systematic random sample of visits is recorded on a standardized encounter form and checked for completeness by NCHS field staff. Sampled physicians complete 30 records per sampling week.

The NHAMCS collects information on patient visits to nonfederal hospital outpatient departments and hospital emergency departments. The data from hospital emergency departments were not used in this study. NHAMCS incorporates a multistage probability design, accounting for geographic primary sampling units, hospital outpatient departments within primary sampling units, and clinics within outpatient departments. The final sampling stage involves systematic random samples of outpatient department visits during randomly assigned 4-week reporting periods.

The response rate for physicians sampled in NAMCS and hospital outpatient departments sampled in NHAMCS between 1999 and 2008 ranged from $63 \%$ to $60 \%$ and $82 \%$ to $83 \%$, respectively. ${ }^{15,16}$ Quality control was performed on $10 \%$ of the sample records using a 2-way independent verification procedure. Item nonresponse rates are $\leq 5 \%$ for most variables. For this study, major exceptions include race (18\% to $33 \%$ annual nonresponse rates) and ethnicity (22\% to $35 \%$ annual nonresponse rates). The NAMCS staff imputed missing data to help compensate for nonresponse to items involving race and ethnicity. Imputation was performed by randomly assigning a value from a patient record form with similar characteristics.

The NCHS weights each visit to allow extrapolation to national estimates for all aspects of the survey. The weights account for practices that were invited to participate but declined to do so. $\mathrm{Na}$ tional estimates are considered reliable with a standard error of $\leq 30 \%$, which generally corresponds to a sample of at least 30 patient visits. ${ }^{15}$ The NCHS institutional review board approved the protocol, including a waiver of the requirement for informed consent.

\section{Creation of Variables}

We examined all ambulatory visits with a primary purpose of gynecological examination (International Classification of Diseases, Ninth Revision, Clinical Modification [ICD-9-CM] codes V72.3, V72.31) and routine cervical Papanicolaou test (ICD-9-CM code V76.2) and considered these to represent preventive gynecologic visits. ${ }^{17}$ Inclusion criteria included these preventive gynecologic visits made by women $\geq 18$ years old. A variable was created and defined as concurrent medical diagnosis, indicating whether the secondary or tertiary diagnoses included a medical condition or nonpreventive gynecologic condition addressed during the preventive gynecologic visit. These concurrent diagnoses were classified by ICD-9-CM codes in the following categories: infectious and parasitic disease (ICD-9-CM codes 001-139); neoplasm (codes 140-239); endocrine and metabolic diseases (codes 240-279); mental health disorders (codes 290$319)$; diseases of circulatory system (codes 390459); nervous system and sense organs (codes 320 389); respiratory system (codes 460-519); digestive system (codes 520-579); genitourinary system (codes 580-629); skin and subcutaneous tissue (codes 680-709); musculoskeletal system (codes 710-739); symptoms, signs, and ill-defined conditions (codes 780-799); and factors influencing health status and contact with health services (codes 800-999). Concurrent diagnoses in the following diagnostic categories were not analyzed separately 
because of insufficient numbers for analysis: disease of blood and blood-forming organs (ICD-9-CM codes 280-289) ( $\mathrm{n}=12)$; congenital anomalies (codes $740-759)(\mathrm{n}=2)$, and injury and poisoning (codes 800-999) $(\mathrm{n}=16)$. The rate of concurrent medical diagnosis occurring during a preventive gynecologic visit represented the primary outcome of the study.

The diagnostic codes used in the NAMCS/ NHAMCS are not derived from billing information. Rather, physicians list diagnoses on a 1-page survey form near the time of the office visit, which then are coded by staff at the NCHS central office. Survey participants are instructed that the intention is to capture the clinical scope of the encounter rather than the order or number of problems that would result in the highest level of billing.

Provider variables include self-selected specialty. Physician specialty was categorized as a visit occurring with either a primary care physician or obstetrician-gynecologist. Primary care physicians included visits occurring at a family medicine $(67 \%)$, internal medicine $(21 \%)$, or general medical clinic $(12 \%)$. In addition, visits were further categorized by whether the visit occurred with the patient's primary care physician and based on the provider's response to the question.

Clinical and demographic data, including age, insurance status, and race, were collected for each visit and de-identified. ${ }^{16}$ Clinical variables included the primary diagnosis and $\leq 2$ secondary diagnoses coded according to the ICD-9-CM. ${ }^{17}$ The NCHS divides the country into 4 geographical regions: Northeast, South, Midwest, and West. Rural locations were identified based on the designations of non-metropolitan statistical areas (MSAs) by the US Office of Management and Budget. An MSA is defined as a county or group of contiguous counties that contains at least one city with a population of $\geq 50,000$ or an urbanized area with a metropolitan population $>100,000 .^{18}$

\section{Statistical Analysis}

We calculated standard errors for all results, as recommended by the NCHS, using STATA software version 10 (StataCorp, LP, College Station, TX). ${ }^{16}$ STATA was programmed with the masked survey design variables to account for the complex multistage sample design and weighting calculations that allow for making population estimates and generation of variance estimates that result in conservative tests of significance. ${ }^{19}$ We evaluated categorical variables with the $\chi^{2}$ test. Multivariate logistic regression was performed to examine the rate of a concurrent medical diagnosis occurring during a visit with a primary purpose of gynecologic examination or Papanicolaou test by specialty. All $P$ values are 2 -tailed; $P<.05$ was considered significant.

\section{Results}

A total of 7882 sample records met the inclusion criteria for the study. These sample records represented an estimated 271 million (95\% confidence interval [CI], 234-309) preventive gynecologic visits in the United States between 1999 and 2008, with approximately 29.6 million (95\% CI, 24.9$34.3)$ visits to primary care physicians and 242 million (95\% CI, 208-275) visits to obstetricians/gynecologists. Obstetrician-gynecologists accounted for $81.2 \%$ of total preventive gynecologic visits, whereas primary care physicians accounted for $18.8 \%$ of the total.

Characteristics of the preventive gynecologic visits grouped by physician specialty are represented in Table 1. Visits to primary care physicians tended to be made by patients between the ages of 45 and 69 years, with higher rates of Medicaid insurance and self-pay status, and were significantly more likely to occur in non-MSAs and in the Midwest and West geographic regions, compared with obstetrician-gynecologists $(P<.05)$. Preventive gynecologic visits were made to primary care physicians who the patient was significantly more likely to consider her designated personal primary care physician compared with obstetrician-gynecologists $(89.7$ vs $14.9 \% ; P<.001)$.

\section{Rate of Concurrent Medical Diagnoses Occurring During Preventive Gynecologic Visits}

Multivariate logistic regression modeling was performed to determine whether a preventive gynecologic visit included a concurrent medical diagnosis (Table 2). After adjusting for demographic and insurance variables, primary care physicians were 2.41 times as likely to include a concurrent medical diagnosis during a preventive gynecologic visit compared with obstetrician-gynecologists (odds ratio [OR], 2.41; 95\% CI, 1.63-3.57). In a similar way, primary care physicians were 3.29 times as likely to include more than one concurrent medical 
Table 1. Characteristics of Preventive Gynecologic Visits to Primary Care Physicians and ObstetricianGynecologists, 1999 to $2008(\mathrm{n}=7882)$

\begin{tabular}{|c|c|c|c|}
\hline \multirow[b]{2}{*}{$\begin{array}{l}\text { Patient } \\
\text { Characteristics }\end{array}$} & \multicolumn{2}{|c|}{ Proportion of Visits (\%) } & \multirow[b]{2}{*}{$\begin{array}{c}P \\
\text { Value }\end{array}$} \\
\hline & $\begin{array}{c}\text { Primary } \\
\text { Care } \\
\text { Physicians* } \\
(\mathrm{n}=1479)\end{array}$ & $\begin{array}{l}\text { Obstetrician- } \\
\text { Gynecologists } \\
(\mathrm{n}=6403)\end{array}$ & \\
\hline \multicolumn{4}{|l|}{ Age, years } \\
\hline $18-29$ & 20.3 & 21.7 & $<.05$ \\
\hline $30-44$ & 30.9 & 36.6 & \\
\hline $45-69$ & 45.1 & 37.5 & \\
\hline$>69$ & 3.7 & 4.3 & \\
\hline \multicolumn{4}{|l|}{ Race } \\
\hline White & 84.7 & 85.1 & .94 \\
\hline Black & 11.9 & 11.3 & \\
\hline Asian and other & 3.4 & 3.6 & \\
\hline \multicolumn{4}{|l|}{ Ethnicity } \\
\hline Latino & 12.6 & 11.2 & .53 \\
\hline \multicolumn{4}{|l|}{ Health insurance } \\
\hline Private & 73.4 & 81.8 & $<.001$ \\
\hline Medicare & 7.0 & 6.7 & \\
\hline Medicaid & 7.6 & 5.6 & \\
\hline Other $^{\dagger}$ & 12.0 & 5.9 & \\
\hline \multicolumn{4}{|l|}{ Geographic region } \\
\hline Northeast & 19.5 & 22.0 & $<.001$ \\
\hline Midwest & 30.4 & 20.0 & \\
\hline South & 26.6 & 40.4 & \\
\hline West & 23.5 & 17.6 & \\
\hline \multicolumn{4}{|l|}{ Geographic entity } \\
\hline $\begin{array}{l}\text { Not a metropolitan } \\
\text { statistical area }\end{array}$ & 15.4 & 7.9 & $<.05$ \\
\hline \multicolumn{4}{|l|}{$\begin{array}{c}\text { Visit occurred with } \\
\text { primary care } \\
\text { physician }\end{array}$} \\
\hline Yes & 89.7 & 14.9 & $<.001$ \\
\hline No & 6.6 & 79.3 & \\
\hline Unknown & 3.7 & 5.8 & \\
\hline
\end{tabular}

*Includes family medicine (67\%), internal medicine (21\%), and general medicine clinic (12\%).

${ }^{\dagger}$ Includes self-pay (36\%), charity (24\%), not specified (24\%), unknown $(15 \%)$, and worker's compensation $(<1 \%)$.

diagnoses during the preventive gynecologic visit compared with obstetrician-gynecologists (OR, 3.29; 95\% CI, 2.00-5.42).

Primary care physicians were significantly more likely to include a concurrent medical diagnosis for 6 ICD-9-CM diagnostic categories, including endocrine/metabolic diseases (OR, 8.13; 95\% CI, 3.82-17.31); mental disorders (OR, 2.77; 95\% CI, $1.38-5.59)$; diseases of circulatory system (OR, 3.78; $95 \% \mathrm{CI}, 1.89$ to 7.35$)$; diseases of respiratory system (OR, 14.5; 95\% CI, 4.85-43.56); diseases of digestive system (OR, 6.05; 95\% CI, 2.97-12.32); and diseases of skin and subcutaneous tissue (OR, 4.61; 95\% CI, 1.34-15.8). Of note, within the diagnostic category of genitourinary system diseases, primary care physicians and obstetrician-gynecologists included an equal rate of concurrent diagnoses during the preventive gynecologic visit $(12.0 \%$ vs $12.2 \%)$.

\section{Discussion}

Primary care physicians were 2.41 times more likely to include one or more concurrent medical diagnoses during a preventive gynecologic visit compared with obstetrician-gynecologists (OR, 2.41; 95\% CI, 1.63-3.57). Primary care physicians were significantly more likely to include one or more concurrent medical diagnosis for 6 ICD9-CM diagnostic categories, including mental disorders and diseases of the endocrine/metabolic, circulatory, respiratory, and digestive systems and the skin $(P<0.001$ for each).

Previous studies demonstrate that women are unlikely to receive comprehensive preventive services in a single non-illness-related visit and that use of multiple providers for primary care services is more costly. ${ }^{10,20}$ Our findings further indicate that women who receive preventive gynecologic care from primary care physicians may receive more coordinated, comprehensive health care because multiple medical issues are addressed during the encounter. Preventive gynecologic visits may represent the sole time during a year that women seek health care and therefore represent a chance to address coexisting diseases that do not involve the female reproductive system, such as disorders of the endocrine or circulatory systems or mental health disorders. It is plausible that acute or chronic complaints not addressed during preventive gynecologic visits may represent a missed opportunity for some women.

This analysis is unable to answer the question of whether those women seen by obstetrician-gynecologists for preventive gynecologic visits had subsequent visits with other health care providers at which additional screening, treatment, and counseling of nongynecologic diseases were completed. However, a woman's need to rely on multiple visits, often with multiple physicians, throughout their life for primary health care needs conflicts with the current principles and ideals of the patient-centered medical home. ${ }^{1-4,20}$ 
Table 2. Rate of Concurrent Medical Diagnosis Occurring During Preventive Gynecologic Visits with Primary Care Physicians versus Obstetrician-Gynecologists, by ICD-9-CM Diagnostic Category $(\mathbf{n}=\mathbf{7 8 8 2})$

\begin{tabular}{|c|c|c|c|}
\hline $\begin{array}{l}\text { Concurrent Diagnoses (ICD-9-CM Diagnostic } \\
\text { Category)* }\end{array}$ & $\begin{array}{l}\text { Visits to Primary } \\
\text { Care Physicians } \\
(\%)(\mathrm{n}=1479)\end{array}$ & $\begin{array}{l}\text { Visits to Obstetrician- } \\
\text { Gynecologists (\%) } \\
(\mathrm{n}=6403)\end{array}$ & $\begin{array}{l}\text { Adjusted Odds Ratio } \\
\text { (95\% CI) }\end{array}$ \\
\hline Total concurrent visits (001-999) & 52.9 & 29.6 & $2.41(1.63-3.57)$ \\
\hline Total visits with multiple concurrent diagnosis (001-999) & 23.3 & 8.1 & $3.29(2.00-5.42)$ \\
\hline Infectious and parasitic diseases (001-139) & 2.9 & 1.6 & $1.33(0.47-3.78)$ \\
\hline Neoplasm (140-239) & 1.4 & 0.7 & $1.13(0.30-4.28)$ \\
\hline Endocrine and metabolic diseases (240-279) & 8.4 & 1.6 & $8.13(3.82-17.31)$ \\
\hline Mental disorders (290-319) & 6.1 & 1.4 & $2.77(1.38-5.59)$ \\
\hline Diseases of circulatory system (390-459) & 6.7 & 1.0 & $3.78(1.89-7.35)$ \\
\hline Diseases of respiratory system (460-519) & 2.6 & 0.2 & $14.5(4.85-43.56)$ \\
\hline Diseases of digestive system (520-579) & 2.8 & 0.6 & $6.05(2.97-12.32)$ \\
\hline Diseases of genitourinary system (580-629) & 12.0 & 12.2 & $1.28(0.78-2.10)$ \\
\hline Diseases of skin and subcutaneous tissue (680-709) & 4.2 & 0.5 & $4.61(1.34-15.8)$ \\
\hline Symptoms, signs, and ill-defined conditions (780-799) & 5.6 & 2.5 & $2.13(0.98-4.63)$ \\
\hline $\begin{array}{l}\text { Factors influencing health status and contact with health } \\
\text { services (800-999) }\end{array}$ & 12.6 & 11.6 & $1.12(0.65-1.92)$ \\
\hline
\end{tabular}

*The following categories were not analyzed separately because of insufficient numbers: disease of blood and blood forming organs (ICD-9-CM 280-289), congenital anomalies (ICD-9-CM 740-759), and injury and poisoning (ICD-9-CM 800-999).

${ }^{\dagger}$ Adjusted for race, ethnicity, age, metropolitan statistical area status, insurance, and primary care physician status. CI, confidence interval.

Obstetrician-gynecologists are well equipped to provide preventive gynecologic health care to women of all ages. However, primary care encompasses a much broader scope of care than preventive services, including the ability to initially evaluate and treat a variety of presenting problems. ${ }^{7,21,22}$ Similar to obstetrician-gynecologists' primary care practice patterns found by Coleman et $a{ }^{23}$ we found that primary care physicians were significantly more likely than obstetrician-gynecologists to address the following diagnoses during a preventive gynecologic visit: mental disorders and endocrine/metabolic, circulatory, respiratory, digestive, and skin/subcutaneous diseases. ${ }^{23}$ Primary care physicians addressing concurrent nongynecologic medical issues is a component of receiving continuous, comprehensive women's health care.

Our analysis of this nationally representative database has several inherent limitations. We are unable to address any outcomes or quality of care, which might affect the interpretation of the study findings, recognizing that the ultimate goal of coordinated and comprehensive care is improved health outcomes. Second, NAMCS data provide a snapshot of a single visit rather than tracking individual patients over time, making it impossible to determine whether obstetrician-gynecologists may have recognized concurrent medical problems but referred patients to another provider for management. This practice of referring to another physician would still signify a less timely and less comprehensive approach to care and thereby does not detract from the study conclusions. In addition, NAMCHS categorizes specialty as only general medical clinic, not allowing for any individual analysis of specialty by internal medicine or family medicine. The NAMCS database contains limited data on the contribution of mid-level providers to outpatient preventive gynecologic visits, prohibiting any analysis of visits made to independently functioning nurse practitioners or midwives. Last, in this database rural status was considered to be non-MSA as defined by the US Office of Management and Budget. ${ }^{18}$ This designation, however, occurs at the county level and may actually misclassify smaller, rural areas as urban if they are located within a county considered to be an MSA.

\section{Conclusion}

Primary care physicians are significantly more likely to address concurrent medical problems during preventive gynecologic visits compared with obstetrician-gynecologists. These findings demonstrate the vital role of primary care physicians in 
providing accessible and coordinated health care to women and fulfilling the key tenets of the patientcentered medical home. ${ }^{1-4}$ Providing patient centered care to women may require improved coordination between primary care physicians and obstetrician-gynecologists to ensure that women receive comprehensive care. A potential patientcentered model of care may include having multidisciplinary sites where women have access to different providers who can work together to provide optimal care at one site. As US health systems increasingly adopt these patient-centered principles, the role of primary care in meeting the unique needs of women's health should be considered to provide women with comprehensive preventive and primary care within the medical home. For women, this may prove to be a critical factor as they strive to ensure that both their gynecologic and nongynecologic health needs are addressed.

\section{References}

1. Patient-Centered Primary Care Collaborative. Defining the medical home. Available from: http:// www.pcpcc.net/content/joint-principles-patientcentered-medical-home. Accessed January 18, 2012.

2. Patient centered medical home resource center. Defining the PCMH. Available from: http://pcmh.ahrq.gov/ portal/server.pt/community/pcmh__home/1483/ PCMH_Defining\%20the\%20PCMH_v2. Accessed February 9, 2012.

3. Stange KC, Nutting PA, Miller WL, et al. Defining and measuring the patient-centered medical home. J Gen Intern Med 2010;25:601-12.

4. Davis K, Schoenbaum SC, Audet AM. A 2020 vision of patient-centered primary care. J Gen Intern Med 2005;20:953-7.

5. Clancy CM, Massion CT. American women's health care: a patchwork quilt with gaps. JAMA 1992;268: 1918-20.

6. Bartman BA, Weiss KB. Women's primary care in the United States: a study of practice variation among physician specialties. J Womens Health 1993; 2:261-8.

7. Hurd WW, Barhan SM, Rogers RE. Obstetriciangynecologist as primary care provider. Am J Manag Care 2001;7(Spec No):SP19-24.

8. Bean-Mayberry BA, Chang CH, McNeil MA, Scholle SH. Ensuring high-quality primary care for women: predictors of success. Womens Health Issues 2006;16:22-9.

9. Henderson JT, Weisman CS, Grason H. Are two doctors better than one? Women's physician use and appropriate care. Womens Health Issues 2002;12: $138-49$.
10. Scholle SH, Chang JC, Harman J, McNeil M. Trends in women's health services by type of physician seen: data from the 1985 and 1997-98 NAMCS. Womens Health Issues 2002;12:165-75.

11. Weisman CS, Henderson JT. Managed care and women's health: access, preventive services, and satisfaction. Womens Health Issues 2001;11:201-5.

12. Sonenstein FL, Ku L, Schulte MM. Reproductive health care. Patterns in a changing market. West J Med 1995;163(3 Suppl):7-14.

13. Lentz GM, Ayala L, Eckert LO. A comprehensive women's health care center: are gynecologists offering primary care? Am J Obstet Gynecol 2006;194: 1660-6.

14. Wise PH. Transforming preconceptional, prenatal, and interconceptional care into a comprehensive commitment to women's health. Womens Health Issues 2008;18(6 Suppl):S13-8.

15. Cherry DK, Hing E, Woodwell DA. National Ambulatory Medical Care Survey: 2006 summary. Adv Data 2008;(3):1-40.

16. National Center for Health Statistics. Public use microdata file documentation, National Ambulatory Medical Care Survey, 2008. Hyattsville, MD: National Technical Information Service; 2010.

17. International Classification of Disease, Ninth Revision, Clinical Modification. Available from: http:// www.cdc.gov/nchs/icd $/$ icd $9 \mathrm{~cm} . h \mathrm{htm}$. Accessed November 14, 2013.

18. National Archives and Records Administration, Office of Management and Budget. Standards for defining metropolitan and micropolitan statistical areas. December 2000. Available from: http://www.whitehouse. gov/omb/fedreg/metroareas 122700.pdf. Accessed April 1, 2007.

19. Hing E, Gousen S, Shimizu I, Burt C. Guide to using masked design variables to estimate standard errors in public use files of the National Ambulatory Medical Care Survey and the National Hospital Ambulatory Medical Care Survey. Inquiry 2003;40: 416-5.

20. Bartman BA, Clancy CM, Moy E, Langenberg P. Cost differences among women's primary care physicians. Health Aff (Millwood) 1996;15:177-82.

21. American Academy of Family Physicians. Primary care. Available from: http://www.aafp.org/online/ en/home/policy/policies/p/primarycare.html. Accessed December 15, 2011.

22. Stovall DW, Loveless MB, Walden NA. Primary and preventive healthcare in obstetrics and gynecology: a study of practice patterns in mid-atlantic region. J Womens Health 2007;16:134-8.

23. Coleman VH, Laube DW, Hale RW, Williams SB, Power ML, Schulkin J. Obstetrician-gynecologists and primary care: training during obstetrics-gynecology residency and current practice patterns. Acad Med 2007;82:602-7. 